\title{
Top-class, new generation sediment coring on Research Vessel Marion Dufresne
}

\author{
Denis-Didier Rousseau', H. Leau², Y. Réaud ${ }^{3}$, X. Crosta ${ }^{4}$ and M. Calzas ${ }^{3}$
}

\begin{abstract}
Over the last 20 years, the PAGES-endorsed IMAGES program (International Marine Past Global Change Study, http://www. images-pages.org/) supported 18 sea-going expeditions onboard the 120-meter-long Research Vessel Marion Dufresne. This vessel, operated by the French Paul-Emile Victor Polar Institute, was equipped with an in-house-developed, unique sediment coring facility, called CALYPSO, which allowed for the retrieval of high-quality, long marine cores at sites of high sedimentation rates. The vessel currently holds the world record for the longest marine core ever retrieved $64.5 \mathrm{~m}$. These cores enabled the comparison of marine and ice-core records at the same resolution for the first time, and tremendously improved the understanding of past oceans dynamics.
\end{abstract}

After 20 years of existence, both the coring system and the vessel were upgraded (Fig. 1) in an initiative funded by the French government to provide the scientific community with top-notch technological marine support for the new generation of coring tools. The new coring equipment, developed within the CLIMCOR project (http://climcor-equipex.dt. insu.cnrs.fr/?lang=en), provides the chance to collect high-quality oceanographical data as crucial complements for paleoclimatic data.

The objective is to routinely retrieve 75-meter-long, undisturbed sediment cores in any water depths to adequately address the scientific targets highlighted by international scientific programs. To achieve this, a specially designed DYNEEMA synthetic cable, with controlled minimum elasticity, has been developed to drastically reduce the sediment disturbance upon coring of the top meters of the core, which was the main flaw of the previous coring system. The first sea trials, operated in November 2015, show that when the corer is triggered just above the seabed at a water depth of $4500 \mathrm{~m}$, the elastic rebound of the cable has been strongly reduced from 16 to 9 meters. This elastic rebound is due to the sudden release of the corer weight that was set to five tons for this test. This minimized elastic rebound should now guarantee undisturbed sediment recovery down to $4000 \mathrm{~m}$ water depth.

Other technical improvements lead to better control of the operation with a suite of pressure and acceleration sensors on the corer head and the triggering system, and software (e.g. CINEMA software developed by Ifremer; Bourillet et al. 2007; Woerther et al. 2012), allowing a detailed monitoring of the coring operation, increased safety of the operation both for the personnel and in strumentation, an optimization of ship time, and a larger choice of environment-data collection during the coring process, including detailed information on the degree of preservation of the recovered sediment sequence.

During its midlife refit, the vessel was adapted to suit this new long-core challenge.

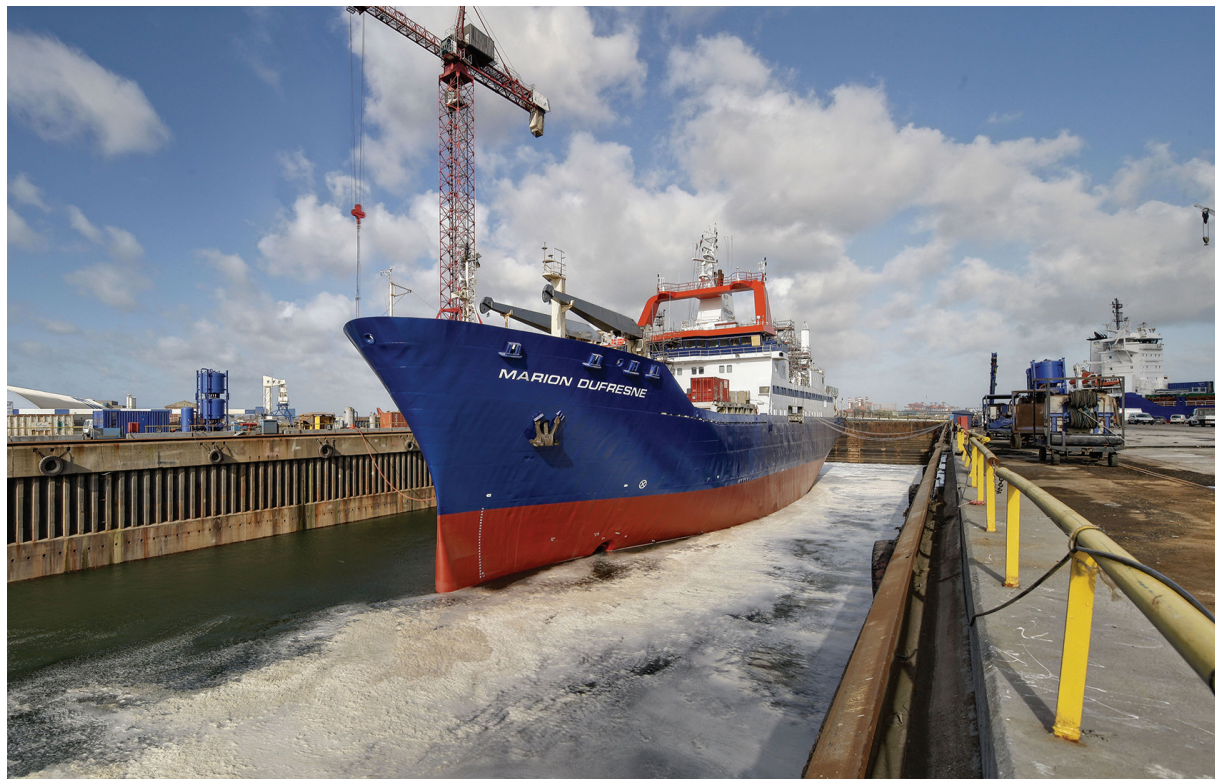

Figure 1: Research Vessel Marion Dufresne in dry dock during her complete refit (photo by Damen Shiprepair Dunkerque).
Scientific deck equipment, such as the coring winch and associated frame, the hydrological winch and the deployment system were upgraded. The coring handling equipment capacity was increased to 45 tons SWL (Safe Working Load) and the ship bulwark was modified to allow easier and safer deployment of a 75-meter-long corer.

Finally, a new suite of acoustic sensors was integrated on board the vessel, including KONSBERG EM122 and EM710 multibeam echo-sounders and a SBP 120-3 sub-bottom profiler. This equipment provides the highest image quality of the seabed and upper sediment, allowing an accurate survey of the coring targets. A new Ultra Short Base Line system (USBL Posidonia) was integrated to accurately locate the various corers on the seabed.

Due to the massive investment through the "Investissements d'Avenir" French national program, the refitted Marion Dufresne offers brand new and top-class coring equipment, able to collect up to 75-meter-long continuous sequences of undisturbed sediments at water depths as deep as $4500 \mathrm{~m}$, which is available to the international paleoceanographic and paleoclimate communities for upcoming exciting and stimulating expeditions.

\section{AFFILIATIONS}

${ }^{1}$ Ecole Normale Supérieure, LMD, Paris, France ${ }^{2}$ French Polar Institute Paul Emile Victor, Plouzané, France

${ }^{3}$ CNRS, National Institute for Earth Sciences and Astronomy, Paris, France

${ }^{4}$ Bordeaux University, EPOC, Pessac, France

\section{CONTACT}

Denis-Didier Rousseau: denis.rousseau@Imd.ens.fr

LINKS

http://climcor-equipex.dt.insu.cnrs.fr/

http://www.cnrs.fr/

http://www.institut-polaire.fr/

http://www.agence-nationale-recherche.fr/

investissements-d-avenir/

\section{REFERENCES}

Bourillet J-F et al. (2007) 6th International Conference on Offshore Site Investigation and Geotechnics: Confronting New Challenges and Sharing Knowledge. Society of Underwater Technology، London, UK

Woerther P et al. (2012) Improving in piston coring quality with acceleration and pressure measurements and new insights on quality of the recovery INMARTECH 2012, Texel, the Netherlands 